\title{
Production Improvement Efforts by Doing Condensate Trap from Gas Flare on EPF (Early Production Facilities)
}

\author{
Edgie Yuda Kaesti1 ${ }^{1, *}$, Heriyanto ${ }^{1}$, Theomas Abdi Jaya ${ }^{1}$, Michael Janzen Arinatama ${ }^{1}$, \\ Adha Bayu Wijaya ${ }^{2}$ \\ ${ }^{1}$ Petroleum Engineering, UPN "Veteran” Yogyakarta, Sleman, Indonesia \\ ${ }^{2}$ Production Engineer, Production and Operation Department of Pertamina EP Asset 4 Field \\ Cepu, Blora, Indonesia \\ Corresponding author: a)edgieyuda@upnyk.ac.id
}

\begin{abstract}
.
Field "X" one of the oil and gas fields was have 3 operating wells. The daily production of oil and gas up to April 27, 2019, was 215 BOPD and gas was 0.15 MMSCFD, where previously the produced gas was discharged by flare and oil was flowed directly to the collecting station. The problem with this research is that the original gas in the flare still contains hydrocarbon compounds and water which is marked on a black-coloured flaring fire. Therefore, the researchers innovated that the gas production of the " $\mathrm{X}$ " Field that had previously only been removed (flaring) would be converted to be produced into condensate and could reduce $\mathrm{CO}_{2}$. The methodology in this study begins by determining the composition of gas by using the Gas Chromatograph tool. Then a simulation is performed to obtain condensate recovery with the help of the Process Simulation software, by which trial and error methods are applied. This study uses two types of heat exchanger devices, namely fin-fan and chiller. Device with the most produced condensate is chosen for further study and field application. The results are based on simulation with consideration to temperature and pipe size sensitivity. The gas
\end{abstract}


production of 0.15 MMSCFD from the "X" Field can produce condensate of 4.10 BBL of condensate by using a chiller. The chiller is the most representative tool for conducting this condensation process after being validated using software simulation process. The application of chiller will eliminate the need of gas scrubber, hence creating more affordable facility and the produced condensate can be sold. The absence of gas scrubber can save cost up to $1,370.53 \$$ month and the produced condensate will create additional revenue as much as 205 $\$ /$ day, with the assumption of condensate price constant at $\$ 50$.

Keywords: chiller, condensate trap, early production facilities, fin-fan.

\section{Introduction}

The processing as well as the production stage of crude oil, however sophisticated they may seem, is not $100 \%$ effective and they require flaring to remove the unwanted gas content. The flaring and venting processes are responsible for the loss of gas energy, which can be up to $5 \%$ of the total global supply. Consequently, it creates inefficiency and harm to the environment. The amount of $\mathrm{CO}_{2}$ that is released into the atmosphere reaches 300 million tons per year [12].

Gas flaring is a process of removing natural gas content that is found within crude oil during production stage. The removal process is carried out by burning the gas content. Gas flaring is one of the cheapest, most practical options to remove natural gas, particularly in facilities that are not equipped with the necessary infrastructure to further process the produced gas. However, it generates several environmental concerns, especially for the surrounding environment and its people [2].

Production management towards its scheme and surface equipment play an important role in the upstream part of oil and gas industry. Therefore, it is important to continuously improve the system accordingly and to utilize the use of most recent technology to support the efficiency of the whole production facility. Due to its complexity, production facility can possibly cause problems that can very much disturb the productivity of a field, if not managed properly. This paper focuses on the optimized workflow that can provide high level of efficiency, reducing the unnecessary or less effective equipment, as well as creating condensate production incremental through the utilization of heat exchanger equipment. 
The "X" field is located at Central Java is one of the oil and gas fields. Field "X" has 3 wells, namely \#A, \#B, and \#C wells. Daily oil and gas production from the 3 wells up to April 27, 2019, was 215 BOPD and gas was 0,15 MMSCFD.

This " $\mathrm{X}$ " field can be issued to have a large enough amount of oil and gas production, where previously the produced gas was released by flare and oil was directly flowed to the collection station. Gas production of 0,15 MMSCFD from 3 wells in "X" Field which was previously only spent (burning) will be converted to be produced into condensate.

Gas condensate is a liquid hydrocarbon phase that has high-API gravity and low density generally occurs in general with natural gas [14]. Liquid characteristics are highly dependent on the thermodynamic conditions of the hydrocarbon mixture. A gas treatment with a pressure drop will cause a decrease in density and vice versa. But on the contrary, if the temperature of the gas is lowered then the density will increase and vice versa.

If the condensate gas is changed it will change into two phases, namely the gas and the liquid whose pressure is lowered is reduced at the dew point (dew point). Condensate is a form of liquid hydrocarbon that is mixed with other gaseous components, that are obtained from both gas wells or oil wells. When the pressure condition is at atmospheric pressure, and the temperature is at room temperature, the condensate appears to be identical with gasoline. The liquid form of condensate can be separated from gas by using separation tools, such as separator or scrubber.

The produced gas from the oil wells would normally go directly to the flare where it will be burned. This process is not very efficient as there are still some hydrocarbon within the gas that is producible. The process of obtaining condensate liquid from is obtained by putting a process called "recovery light hydrocarbon liquid" in place. This process has a few different methods, one of which is refrigeration or cooling. Refrigeration itself is a process that reduces the temperature of working condition to the point where it is lower than the dew point of the condensate. By doing so, the previously gas condensate can turn from gaseous phase to liquid phase. This refrigeration process can be performed by installing different equipment, such as fin-fan or Chiller. The equipment selection is crucial to create the most condensate liquid. The selection process depends on various aspects, which include the availability of the resources, the economical values, and the instalment location. In order to obtain the most condensate, a few possible scenarios have to be simulated using Aspen Hysys V.8.8 software. These scenarios mainly focus on different outlet temperatures (sensitivity). 
Hysys itself is a process engineering software that is used in processing equipment simulation. The use of this software extends to many purposes, such as to track equipment problems, to design surface facility, etc.

This study aims to utilize the gas production of 0,15 MMSCFD from 3 wells in the " $\mathrm{X}$ " Field which were previously only disposed of (flaring) to be converted into condensate. The advantage of this condensate production is the company will benefit from sales from condensate production, general profits can meet petroleum needs in Indonesia, and also can reduce the gas waste that contains $\mathrm{CO}_{2}$.

\section{Literature Review}

\subsection{Gas Flare Process.}

Gas flaring is identified as a system to remove gas that is produced, but not necessarily needed for production, by burning it and releasing the product into the atmosphere [12]. Gas flaring can be often seen in production and exploration facility, as well as chemical plants. There are several ways that are utilized to quantize the amount of flared gas. One of them was introduced [13], and has been used since 1935. It mainly correlates the amount of produced oil and flared gas. The abundance of flared gas created innovation and proposal to reduce its number. Odumugbo suggested that in order to reduce its number, the produced gas can be injected back into the ground or the produced gas can be utilized for commercial use [11]. However, the utilization of the produced gas will require more equipment as the gas needs to be liquified and transported properly before it can be distributed. Nowadays, many countries have considered the environmental aspect more seriously. As the result, the utilization of gas flaring is prohibited or limited in many countries. However, the use of gas flaring can always exist, depending on the condition of the field, and certain issues that force the utilization of it. These issues, according to Oil and Gas Producers, include unburned processed gas which is obtained from processing, the inability to transport gas for commercial use due to its excessive amount, accumulated vapors during tank filling process, production shutdown, maintenance, equipment replacement, and upon starting up a facility.

\subsection{Optimization Parameters}

The optimization of this paper's particular field focuses on the installment and the utilization of different equipment and how those variables can improve oil and gas production to create highly valuable condensate. These parameters include: 
- $\quad$ Fin-fan.

Fin-fan is one type of heat exchanger that uses ambient air to cool fluid (air cooler heat exchanger). Heat transfer occurs between the fluid in the tube with the surrounding air without direct contact. The main advantage of a fin-fan is that it does not need water, which means that the equipment needed for cooling does not have to be close to the supply of cold water. In the fin-fan heat transfer that occurs from the fluid to the air around without environmental problems, or without large costs for water supply and maintenance [10]. The design of fin-fan will be showed in Figure-1. as follow.

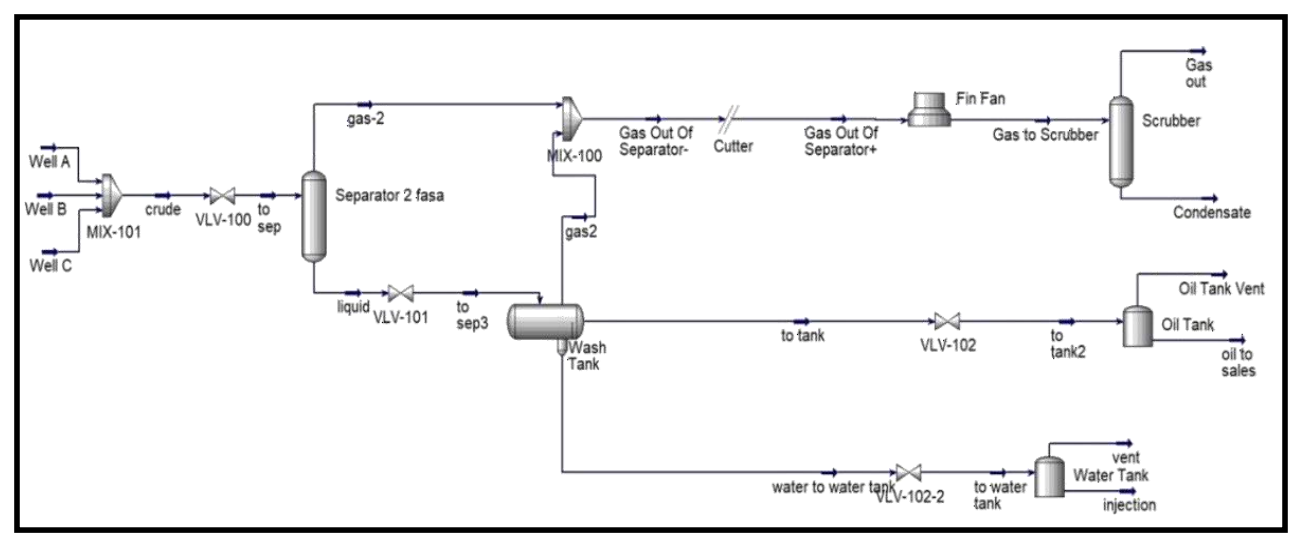

Figure 1. Design of Fin-fan by Using Aspen Hysys V.8.8.

An air-cooled heat exchanger consists of several parts, namely fans and tubes arranged in a bank and driver. The fan functions to supply cooling air to the air cooler, the bank is composed of tubes as a means for process fluids while the driver functions as a fan drive. The heat transfer that occurs at the fin-fan is no more than the ambient air temperature. Therefore, the stability of the ambient air temperature needs to be considered.

- Chiller

Chiller system is a cooling system that uses the liquid as a cooling medium (generally water) in the secondary system where the evaporator in the primary system cools the liquid (chilled water) in the second cycle which will be used to cool the room through the AHU (Air Handling Unit). The primary system is the main cooling unit with the Steam Compression Cycle (SKU) which consists of the main components namely the compressor, condenser, expansion valve, and evaporator. In the Chiller system, a process of expenditure and heat absorption occurs. Water entering the Chiller will be cooled, and circulated by the pump to the AHU. In this unit, there is a heat exchange process between air and cold water. Cold air coming out of this unit will be circulated by the fan to the conditioned room [9]. 


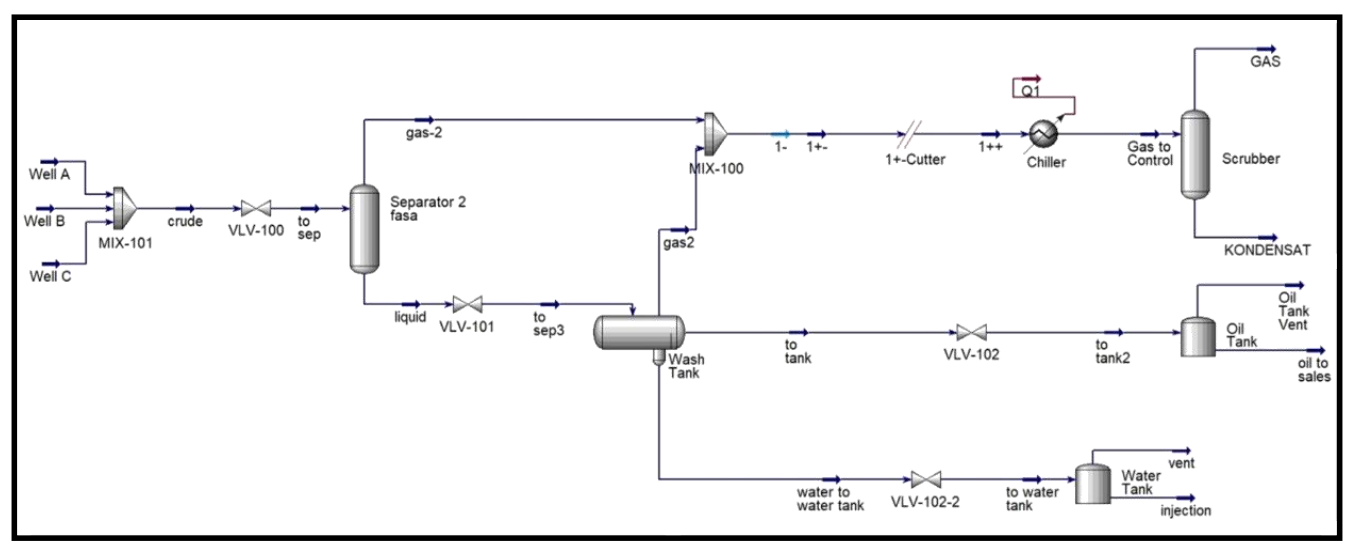

Figure 2. Chiller Design by Using Aspen Hysys V.8.8.

Chiller design in Figure-2. in which there is a device such as a condenser. The condenser is an important component of every cooling system. In a typical Iso-Butane refrigerant condenser [5]. The use of Chiller also requires the use of refrigerant, which is a type of liquid that circulates the temperature of the system by exchanging its temperature with the surrounding. Depending on the condenser's design and the temperature of the external media, refrigerants that escapes the condenser can be in saturated state or sub-cold liquid state. Figure-3 shows different variation of the cooling cycle in the T-s diagram. The heat rejection process is represented by 2-3'-3-4. Refrigerant experiences de-superheating process and significant temperature loss (from the initial temperature and pressure to saturation pressure and temperature) during 2-3'. After that, the 3'-3 process takes place, which is a process of condensation where the temperature ideally remains constant, and the phase changes from gaseous to liquid. the 3-4 process is the sub-cooling process, where the refrigerant will drop its temperature significantly in liquid form.

In this study, the chiller that is used has been modified to allow the gas to flow through the chiller. Gas tubes are installed in the chiller to allow the gas to flow through the chiller, where it will drop its temperature to its dew point, resulting in condensation and condensate as the final product. 


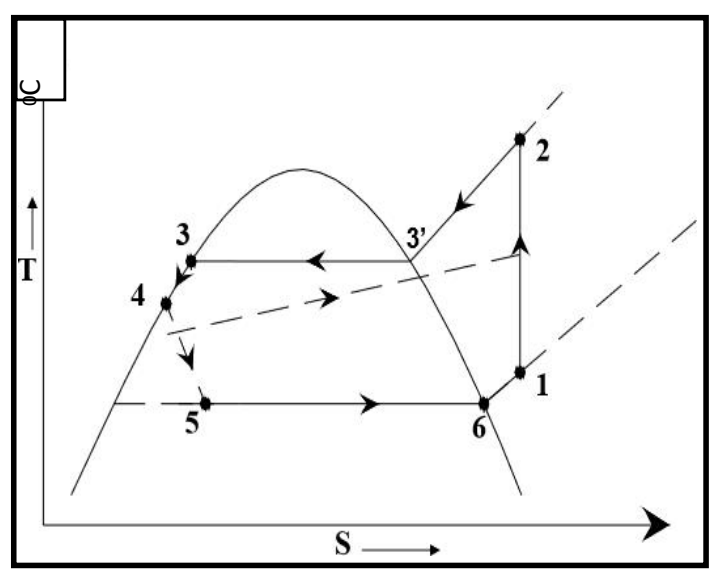

Figure 3. The Cooling Cycle in the Diagram T-s

- $\quad$ Software Aspen Hysys V.8.8.

The simulation in this study uses Aspen Hysys V.8.8. Software. Hysys is a process engineering software that is used in processing equipment simulation. The use of this software extends to many purposes, such as to track equipment problems, to design surface facility, etc. This software allows the simulation to be run in two different methods, which are steady state and dynamic.

\subsection{Environmental Impacts}

There are several findings as to why gas flaring in environmentally dangerous. The products of gas burning consist of carcinogens and heavy metal, as well as the release of carbon dioxide $\left(\mathrm{CO}_{2}\right)$ and methane $\left(\mathrm{CH}_{4}\right)$, which will further worsen global warming and climate change. These gases are known to have increased the average global temperature by about 0.5 degree centigrade in the last 100 years. Based on data acquired from Ministry of Energy and Mineral and Resources, the collective volume of flared gas in Indonesia was around 113 MMSCFD in 2008 [7], surely this is a major concern because of its climatic and environmental hazards. This could lead to catastrophic events such as flooding, rising sea level and tidal waves.

\subsection{Economic Impacts}

Gas flaring is a form of waste of natural resource and carries along huge economic impacts. It reduces the nation's revenue generation. In 2007, Indonesia had wasted 215 MMSCF on gas flaring, making it the $13^{\text {th }}$ highest globally. Consequently, Indonesia was responsible for 12 million tons of $\mathrm{CO}_{2}$ in the atmosphere and US\$ 400 million of annual revenue loss [7]. 


\section{Methodology}

\subsection{Procedure of Research}

This research is a trial and error that will be conducted on the Gas Flare at EPF (Early Production Facilities) Field "X". If this research is successful, it will be developed in other fields in company from this field. In general, this research procedure starts with testing gas produced from three "X" Field wells. This test is carried out with a gas chromatograph, from the test results will be obtained by the gas composition. This gas composition contains only a gas component. Therefore, it needs to be tested again to find out other compositions such as $\mathrm{H}_{2} \mathrm{O}$. Retesting is done by taking samples and testing is done in the laboratory. After the gas composition is known, a simulation is then performed to find out the best way to condense the gas in order to obtain the maximum condensate. The simulation is done using the Aspen Hysys V.8.8 simulator application.

\subsection{Simulation Process}

The simulation in this study uses Aspen Hysys V.8.8. Software. Hysys is a process engineering software that is used in processing equipment simulation. The use of this software extends to many purposes, such as to track equipment problems, to design surface facility, etc. This software allows the simulation to be run in two different methods, which are steady state and dynamic.

In this study, there are two heat exchanger equipment that are tested. This two equipment are Fin-fan and Chiller. the simulation compares the amount of condensate that each equipment can produce. The most produced condensate is achieved when the optimum output temperature is reached. During the simulation process, the gas composition is inputted at each device's process flow. The result shows the amount of produced condensate at different output temperatures, and with the utilization of different equipment [15].

1. Chemical components

The inputted gas components include methane, ethane, propane, n-butane, i-butane, npentane, i-pentane, n-hexane, carbon dioxide, nitrogen, and water.

2.

Thermodynamic Model

The selected thermodynamic model is Peng-Robinson model, as it is highly recommended and often used for gas calculation [6]. This model is able to solve up to three phase systems.

This model is also usable for temperature condition as low as $-271^{\circ} \mathrm{C}$ and pressure below 
15,000 psi. Furthermore, this model also applies the improved binary interaction parameters for all bonds between existing hydrocarbons.

Economic Analysis. This paper will feature its economic analysis to show the advantages of condensation process utilization and how it will further reduce overall cost and increase revenue.

\section{Result and Discussion}

\subsection{Optimization Parameters Field "X" Gas Data Analysis}

Gas in the Field " $\mathrm{X}$ " is obtained from the separation of liquid and gas in a separator. The output gas from the separator is 0,15 MMSCFD with a separator pressure of $17 \mathrm{psig}$ and a temperature of $101^{\circ} \mathrm{F}$. Under these conditions, a mass gas of $1.144,82 \mathrm{lb} / \mathrm{h}$ was obtained with the gas composition as follows:

The following gas composition in field $\mathrm{X}$ has been re-calculated by adding the composition of water $\left(\mathrm{H}_{2} \mathrm{O}\right)$, with Aspen Hysys V.8.8 obtained the overall gas composition as follows:

Table 1. Gas Composition in Field " $X$ " along with Water Content

\begin{tabular}{|c|c|c|c|}
\hline \multirow{2}{*}{ Compositions } & \multicolumn{3}{|c|}{ Value } \\
\cline { 2 - 4 } & \% Mol & \% Vol & \% Mass \\
\hline Nitrogen & 0,001 & 0,001 & 0,001 \\
\hline Carbon Dioxida & 0,010 & 0,016 & 0,020 \\
\hline Methane & 0,112 & 0,183 & 0,080 \\
\hline Ethane & 0,023 & 0,060 & 0,031 \\
\hline Prophane & 0,045 & 0,120 & 0,089 \\
\hline i-Butane & 0,020 & 0,064 & 0,052 \\
\hline n-Buthane & 0,017 & 0,051 & 0,044 \\
\hline i-Penthane & 0,010 & 0,034 & 0,031 \\
\hline n-Penthane & 0,008 & 0,029 & 0,026 \\
\hline Hexane & 0,008 & 0,031 & 0,030 \\
\hline H $2 \mathrm{O}$ & 0,747 & 0,412 & 0,598 \\
\hline Total & 1,000 & 1,000 & 1,000 \\
\hline
\end{tabular}




\subsection{Condensate Recovery Method}

In conducting condensate recovery, it is necessary to carry out a process in order to achieve conditions below the dew point of some hydrocarbon gas components. Because this field "X" gas dew point is unknown, simulations were performed using the Aspen Hysys V.8.8 software by trial \& error using several heat exchanger media, namely air, water, and propane.

\subsection{Optimization Result}

Chiller and fin-fan modification and estimated results show that the application of chiller and fin-fan utilization create better efficiency. It also eliminates the use of other separation equipment such as Sealer and Flare, whilst producing condensate. The main goal of chiller and fin-fan is to reduce the temperature of the produced volatile oil, turning its gaseous phase into condensate, that would o te, compared to fin-fan. These results were obtained through simulation process that used data therwise waste in flare. Chiller shows a better result of converting the gas into condensa that was obtained in the gathering system. The details of each scenario are as follows:

- $\quad$ Fin-fan

Fin-fan or water-cooled exchanger is a heat exchanger method by using ambient air to cool the process fluid. So the lowest temperature that can be achieved is approximately $25^{\circ} \mathrm{C}$. The following are the simulation results using the Aspen Hysys 8.8 software.

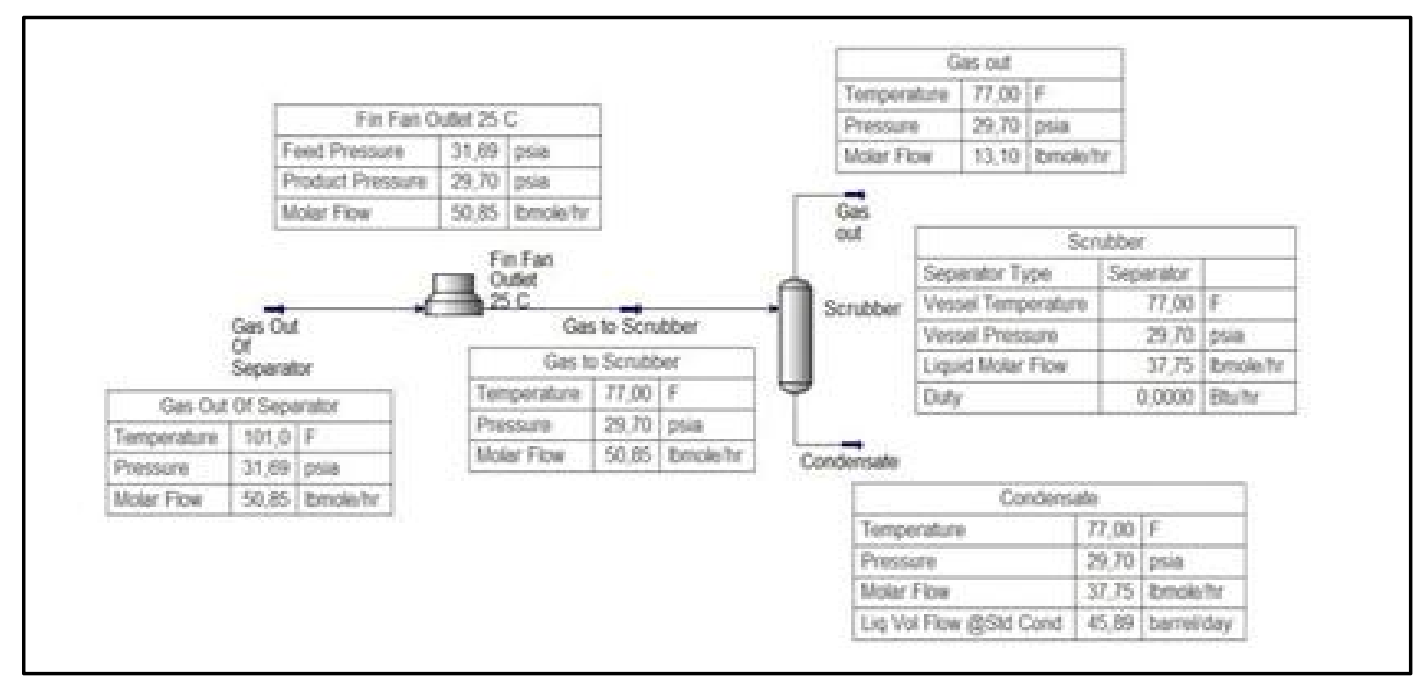

FIGURE 4. Simulation Results with Fin-fan

Judging from Figure-4 from the simulation, there is a condensed component that comes out of the scrubber device through the bottom. The components of condensation include: 


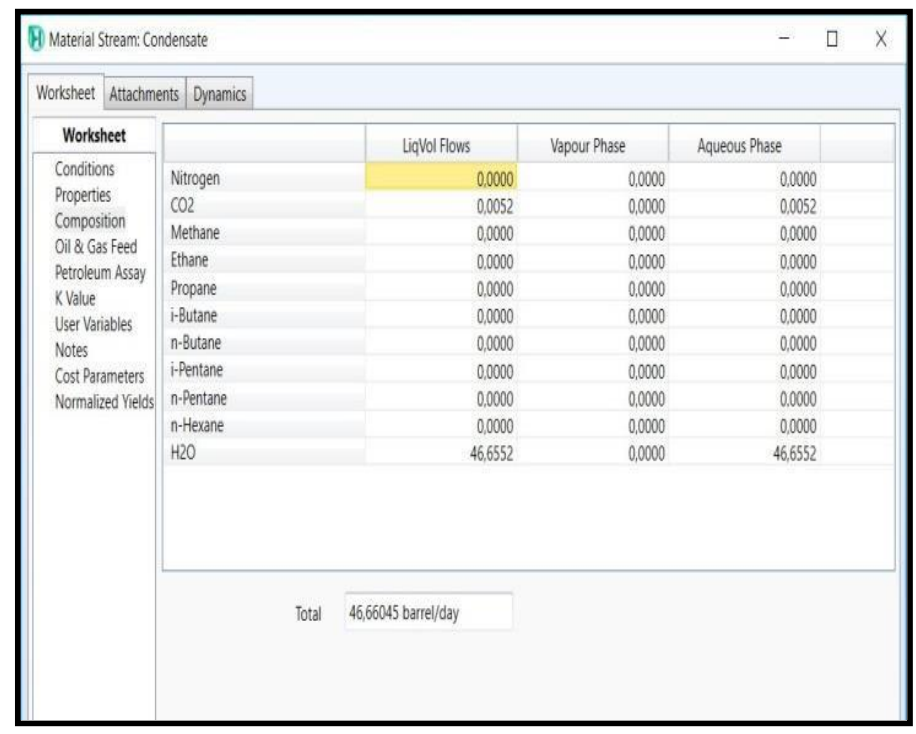

Figure 5. Percentage of Moles of Each Component in the Fin-fan Product

From Figure-5 above, it can be seen that the condensate component is 46,66045 barrels/day. But 46.6552 barrels/day is water and 0.0052 barrels/day is $\mathrm{CO}_{2}$. While the hydrocarbon component is still in the gas phase. This shows that the cooling process fluid is still above the dew point of the hydrocarbon. So this method is not good to use.

\section{- Chiller}

Chiller has the ability to cool the process fluid to temperatures below $0^{0} \mathrm{C}$ so that the target to conduct condensate on the contained condensate is more easily achieved. By performing sensitivity to the outlet temperature, the following results are obtained:

Table 2. Simulation Results Using Chiller with Outlet Temperature Variations

\begin{tabular}{|c|c|c|c|c|}
\hline \multirow{2}{*}{ Parameters } & \multicolumn{4}{|c|}{ Outlet temperature, ${ }^{\mathbf{0}} \mathbf{C}$} \\
\cline { 2 - 5 } & $\mathbf{0}$ & $\mathbf{5}$ & $\mathbf{1 0}$ & $\mathbf{2 5}$ \\
\hline Molar Flow, lb moles/h & 38,76 & 38,42 & 38,08 & 37,06 \\
\hline Cum. Liquid Prod., BLPD & 53,44 & 50,94 & 48,46 & 46,67 \\
\hline $\begin{array}{c}\text { Condensate Prod., } \\
\text { BCPD }\end{array}$ & 6,58 & 4,10 & 1,65 & 0 \\
\hline
\end{tabular}

From the simulations that have been carried out by conducting sensitivity to the Chiller, it can be seen that the components are condensed from various outlet temperatures in Table-2. 


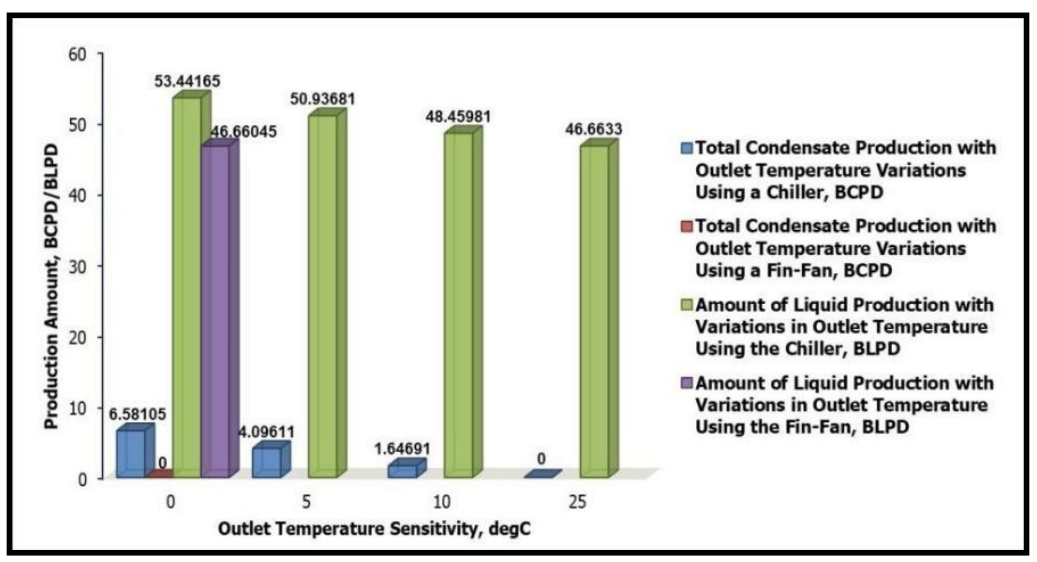

Figure 6. Outlet temperature vs Total Sensitivity of Production from Simulation Result Using Finfan and Chiller with Temperature Variations

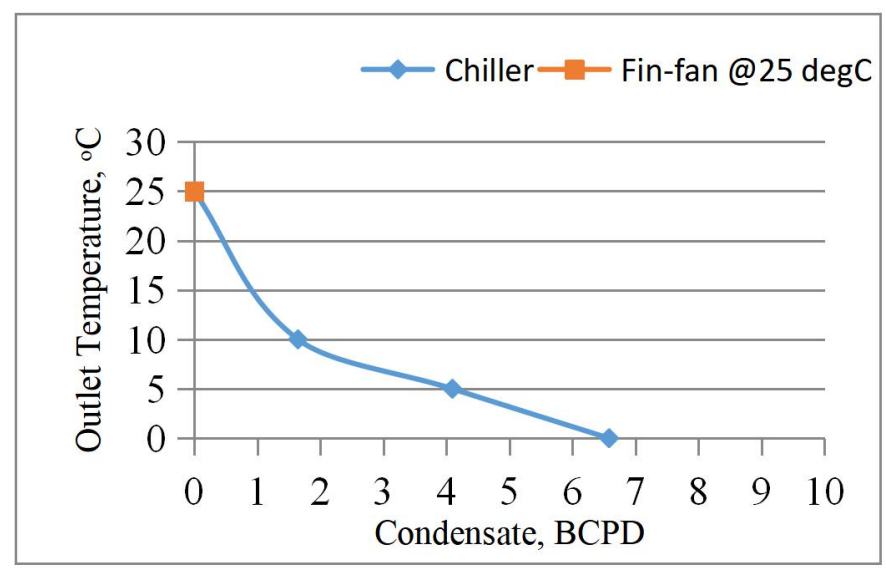

Figure 7. The sensitivity of Outlet temperature vs Condensate Results from Simulation

From Figure-7 of the simulation results, it can be concluded that the smaller the temperature, the greater the condensate produced. In the Chiller with the temperature of $0^{\circ} \mathrm{C}$, the highest total liquid was obtained, which was 53.44 barrels/day and condensate was 6.58 barrels/day.

After comparing different outlet temperatures, we determined the optimum pipe diameter based on minimum pressure drop and maximum result of condensate production. Table 3. below shows the result of pipe sensitivity.

Table 3. Result of Pipe Sensitivity

\begin{tabular}{|c|c|c|c|}
\hline \multicolumn{2}{|c|}{ Diameter (inch) } & $\Delta \mathrm{P}(\mathrm{psia})$ & Condensate (barrel/day) \\
\hline OD & ID & & \\
\hline 6.625 & 5.761 & 0 & 4.10 \\
\hline 4.500 & 3.826 & 0 & 4.10 \\
\hline 2.375 & 1.939 & 0.19 & 4.01 \\
\hline
\end{tabular}


Hereby, we can choose the best pipe diameter which is pipe with OD 4,5 inch and ID 3,826 inch.

\subsection{Economic Analysis}

Required investments include:

1.

2.

3.
Modification of Chiller

Thermostat

Amount

$=\$ 445.42$

$$
=4 \$ / b b l
$$

Saving money from leasing water seals and scrubbers $=1370.53 \$ /$ month

Table 4. Potential Revenue with Assumptions for Condensate Prices 50 \$/bbl

\begin{tabular}{|c|c|c|c|}
\hline $\begin{array}{c}\text { Output Temperature, } \\
{ }^{\mathbf{0}} \mathbf{C}\end{array}$ & Liquid Production & Condensate Production & \multirow{2}{*}{ Income, \$/day } \\
\cline { 2 - 3 } & BLPD & BCPD & 329 \\
\hline 0 & 53.44 & 6.58 & 205 \\
\hline 5 & 50.94 & 4.10 & 82.5 \\
\hline 10 & 48.46 & 1.65 & \\
\hline
\end{tabular}

By applying Chiller in gas processing to condensate from the field " $\mathrm{X}$ ", the company can save on the leasing of water seals and scrubbers used in the previous gas treatment. In addition, condensate sales by the company can make a profit of $\$ 329$ per day at $0^{\circ} \mathrm{C}$ outlet temperature, $\$ 205$ per day at $5^{\circ} \mathrm{C}$ outlet temperature, and $\$ 82.5$ per day at an outlet temperature of $10^{\circ} \mathrm{C}$ with a condensate price of US\$ 50 per barrel of condensate. Where the company only issued capital amounting to $\$ 445.42$ for the planning of making Chiller.

\subsection{Discussion}

This " $\mathrm{X}$ " field produces gas that is separated from the scrubber and the water sealer is directly burned, the combustion results sometimes cause black smoke which indicates that the water molecules are still contained, this is dangerous because it can cause liquid flaring. In addition, there are still light hydrocarbon components if processed again can produce condensate. Therefore, to increase the production of condensate, a gas condensation process from the separator can be carried out. In the simulation activities carried out, the method that uses Fin- 
fan cannot be used because the condensation results only produce $\mathrm{H}_{2} \mathrm{O}$ while the hydrocarbon gas does not condense because it does not reach the dew point of the hydrocarbon.

The method that can be used, namely by using a Chiller. The use of this Chiller can reach temperatures up to $0^{\circ} \mathrm{C}$ so that it will be easier to get hydrocarbon condensation. By doing sensitivity to the outlet temperature of this Chiller it can determine the right temperature to use in order to get the optimum condensate yield.

At an outlet temperature of $10^{\circ} \mathrm{C}$ produces 48.46 BLPD with a condensate of 1.65 BCPD. At an outlet temperature of $5^{\circ} \mathrm{C}$, it produces 50.94 BLPD with condensate of 4.10 BCPD. Whereas the outlet temperature of $0^{\circ} \mathrm{C}$ gets the most production, which is 53.44 BLPD with a condensate of $6.58 \mathrm{BCPD}$. It can be seen with the use of a lower temperature outlet will produce more condensate, but the use of a Chiller with an outlet temperature of $0^{\circ} \mathrm{C}$ needs to pay attention to the freezing point of water. Because if the water freezes up it will cause a plug on the pipewhich will cause backpressure. For this reason, it is necessary to add a unit that functions to separate water from hydrocarbon gases before condensation, which is a dehydration unit that absorbs $\mathrm{H}_{2} \mathrm{O}$ using glycol. In addition, it is also necessary to add a thermostat device that functions to monitor the temperature of this Chiller so that the temperature can be controlled. Based on this paper, we recommend to choose outlet temperature at $5^{\circ} \mathrm{C}$ to prevent pipe plugging that cause back pressure in the pipe. The results from the pipe sensitivity with outlet temperature at $5^{\circ} \mathrm{C}$ is $4,10 \mathrm{BCPD}$, which is pipe with $\mathrm{OD}$ 4,5 inch and ID 3,826 inch.

\section{CONCLUSION}

1. The use of a Chiller is able to reach very low temperatures, by doing sensitivity to the outlet temperature of this Chiller obtained hydrocarbon condensate at a temperature of $0^{\circ} \mathrm{C}$ produces $6.58 \mathrm{BCPD}$, at a temperature of $5^{\circ} \mathrm{C}$ produces $4.10 \mathrm{BCPD}$, and at a temperature of $10^{\circ} \mathrm{C}$ produces $1.65 \mathrm{BCPD}$. The lower the outlet temperature used will produce more hydrocarbon condensate.

2. The freezing point of water needs to be considered, because if using a Chiller with an outlet temperature of $0^{\circ} \mathrm{C}$ causes the water to freeze which can later cause a plug and back pressure can occur.

3. Based on the pipe comparisons we have created, the most optimum pipe 
has OD measurement 4,5 inch and ID measurement 3,826 inch. This pipe will give minimum pressure drop and maximum result of condensate.

4. Based on the economic analysis of the application using Chiller in gas processing to condensate from the Field " $\mathrm{X}$ ", the company can save on leasing water seals and scrubbers used in the previous gas treatment. In addition, condensate sales by the company can make a profit of $\$ 329$ per day at $0^{\circ} \mathrm{C}$ outlet temperature, $\$ 205$ per day at $5^{\circ} \mathrm{C}$ outlet temperature, and $\$ 82.5$ per day at an outlet temperature of $10^{\circ} \mathrm{C}$ with a condensate price of US \$ 50 per barrel of condensate. Where the company only issued capital amounting to \$ 445.42 for the planning of making Chiller and the absence of gas scrubber can save cost up to $1,370.53 \$ /$ month.

5. Considering the technical and economic aspects, a Chiller modification is made and additions and thermostats are made to regulate the temperature so that it remains in its optimum condition. We choose the results from the pipe sensitivity with outlet temperature at $5^{\circ} \mathrm{C}$ is 4,10 BCPD, which is pipe with OD 4,5 inch and ID 3,826 inch and also the produced condensate will create additional revenue as much as $205 \$$ day, with the assumption of condensate price constant at $\$ 50$.

\section{ACKNOWLEDGMENTS}

The author would like to thank to PT. Pertamina Asset 4 Field Cepu, especially to Production and Operation Department that has supported and the opportunity given the data to publish this manuscript. The author also wanted to thank to Petroleum Engineering Department that has supported the author to follow this event.

\section{REFERENCES}

[1] Amrullah, et. al., "Analisa Kinerja Mesin Refrigerasi Rumah Tangga dengan Variasi Refrigeran," 2017.

[2] Aregbe, Azeez G., "Natural Gas Flaring - Alternative Solutions", Journal of Engineering Technology, no. 5, pp. 139 - 15, 2017. DOI: https://doi.org/10.4236/wjet.2017.51012. [Accessed August 2020].

[3] AspenTech, “Official Website of AspenTech Company,” Aspen Technology, 1994-2005. [Online]. Available: www.aspentech.com. 
[4] Aziz, Azridjal, et. al., "Penggunaan Thermal Energy Storage sebagai Penyejuk Udara Ruangan dan Pemanas Air pada Residential Air Conditioning Hibrida," Banjarmasin: Proceeding Seminar Nasional Tahunan Teknik Mesin XIV, 2015.

[5] Aziz, Azridjal and Herisiswanto, "Pengembangan Energy Efficient Residential Air Conditioning Systems dengan Encapsulated Ice Thermal Energy Storage Berbasis Mesin Refrigerasi Kompresi Uap Menggunakan Refrigeran Hidrokarbon Substitusi R-22 yang Ramah Lingkungan,” Pekanbaru: Lembaga Penelitian Universitas Riau, 2009.

[6] Changjun Li, Yang Peng, Jingya Dong, "Prediction of the Dew Point Pressure for Gas Condensate Using a Modified Peng-Robinson Equation of State and a Four-coefficient Molar Distribution Function," Journal of Natural Gas Science and Engineering, Vol. 27, pp. 967-978, 2015. DOI: https://doi.org/10.1016/j.jngse.2015.09.034.

[7] Director General of Oil and Gas, "Pemerintah Targetkan Zero Flare Pada Tahun 2025," Jakarta: Ministry of Energy and Mineral Resources, 2010. [Online]. Available: https://www.esdm.go.id/id/media-center/arsip-berita/pemerintah-targetkan-zero-flarepada-tahun-2025.

[8] Fares, A. D, "Process Simulation Using Aspen HYSYS V.8.8," 2016.

[9] Hudson Product Corporation, "The Basic of Air-Cooled Heat Exchangers," 2007.

[10] Kolmetz, Karl, "Kolmetz Handbook of Process Equipment Design: Fin-fan Air Cooler Selection and Sizing," Malaysia: KLM Technology Group, 2015.

[11] Odumugbo, Charles Asekhame, "Natural Gas Utilisation in Nigeria: Challenges and Opportunities," Chemical Engineering, no. 2, pp. 310 -316, 2010. DOI:

[12] Ojijiagwo, Emeka, et. al., "Economics of Gas to Wire Technology Applied in Gas Flare Management," Engineering Science and Technology, an International Journal, no. 19, pp. 2109 - 2118, 2016. DOI: http://dx.doi.org/10.1016/j.jestch.2016.09.012.

[13] Rotty, Ralph M., "First Estimates of Global Flaring of Natural Gas," Atmospheric Environment, vol. 8, pp. 681 - 686, 1973. DOI: https://doi.org/10.1016/00046981(74)90159-0.

[14] Schlumberger, "Oilfield Dictionary, USA: Schlumberger Limited, 2019. [Online]. Available: https://www.glossary.oilfield.slb.com/Terms/c/condensate.aspx. [Accessed May 2019].

[15] Smith, P. et, al., "Tutorials \& Applications HYSYS 3.1," Cambridge: Aspen Technology, 2002. 
[16] Yusuf, Jefry, Husni Husin, dan Marwan, "Simulasi Pengaruh Kandungan $\mathrm{CO}_{2}$ dalam Ga8s Umpan terhadap Re-forming dan Shift Converter Sistem Pabrik Amoniak," Jurnal Rekayasa Kimia dan Lingkungan, vol. 10, no. 4, pp. 178 - 187, 2015. 